\title{
PELATIHAN SENI KERAJINAN TANGAN DARI BARANG BEKAS DI SDN SUKALELA BAWEAN
}

\author{
${ }^{1}$ Lutfiana Baroditus Sobakhah \\ ${ }^{2}$ Zuhrina Aulia Izzati \\ Universitas Muhammadiyah Gresik \\ Lufiana.sobakhah78@gmail.com
}

\begin{abstract}
ABSTRAK
Tidak semua sekolah dasar mampu memberikan pengajaran seni termasuk seni kerajinan tangan secara optimal, hal itu bisa dilihat dari faktor pendidik yang kurang antusias untuk memberikan pengajaran terhadap seni sehingga peserta didik kurang mampu mengeluarkan kreativitas dan keterampilannya dalam berkarya seni. Pengajaran seni khususnya kerajinan tangan sangat dibutuhkan anak tingkat sekolah dasar untuk perkembangan kreativitasnya, dengan adanya pelatihan seni kerajinan tangan dari barang bekas yang dilakukan oleh mahasiswa KKN dari prodi PGSD di SDN Sukalela kecamatan Tambak Bawean siswa menjadi terampil, aktif, dan mampu menunjukan kreativitasnya serta memahami pemanfaatan barang bekas disekitarnya. Siswa bersama-sama membuat karya dengan arahan dari pengajar dan sesuai dengan contoh yang telah disiapkan sebelumnya. Sasaran yang diberi pengajaran adalah siswa-siswi kelas 3,4,5 dan 6 dengan pembagian har mula dari hari ke-19 sampai hari ke-22. Hasil karya berupa tempat pensil, bunga botol, bunga dari tempat telur.
\end{abstract}

Kata Kunci : Pelatihan Seni Kerajinan Tangan, Barang Bekas

\section{PENDAHULUAN}

Desa Sukalela adalah sebuah desa yang berlokasi di kecamatan Tambak Bawean dan masuk dalam wilayah Gresik. Berdasarkan dari prosentase tentang pekerjaan penduduk tahun 2017, didapat bahwa wiraswasta 257 orang, petani sebanyak 170 orang, guru sebanyak 24 orang, nelayan sebanyak 17 orang, PNS sebanyak 8 orang dan belum bekerja sebanyak 106 orang. Dibidang pendidikan, desa Sukalela memiliki beberapa lembaga pendidikan yaitu TK Dharma Wanita Persatuan dan SDN Sukalela.
Potensi yang dimiliki oleh siswa-siswa SDN Sukalela cukup bagus, mereka mempunyai skill yang beraneka ragam, mulai dari kemampuan bermain volly, sepak bola, memainkan rebana, bermain alat musik, bersholawat, membaca al-qur'an, dan lain-lain. Siswa-siswi di SDN Sukalela mempunyai kemampuan untuk menyerap pengetahuan secara secara cepat, mereka aktif dan cekatan.

Persoalan keterampilan, mereka cukup terampil dalam melakukan sesuatu, hanya saja keterampilan seorang anak tersebut berbedabeda. Pembelajaran yang ada di SDN Sukalela sama dengan pembelajaran di sekolah pada 


\section{JTIEE Vol.1 No. 215 Desember 2017}

umumnya, namun kegiatan ekstrakulikuler maupun pelatihan lainnya belum terlaksana dengan baik. Pelatihan keterampilan bagi anak SD memang sangat diperlukan untuk mendukung daya kreativitasnya serta untuk meningkatkan keterampilannya. Dan seni merupakan salah satu keterampilan yang memacu kecerdasan emosional serta kemampuan berinovasi.

Salah satu keterampilan yang cukup menyenangkan dilakukan oleh anak SD adalah keterampilan tentang membuat kerajinan tangan, namun di SDN Sukalela pelatihan seni kerajinan tangan belum pernah dilaksanakan. Hal itu terjadi karena waktu untuk melakukan pelatihan tersebut belum bisa diatur dengan baik, guru pengajarnya juga belum ada dan kurang semangat untuk melakukan kegiatan tersebut dengan melihat kondisi usia pengajar di SDN Sukalela yang cukup memungkinkan untuk menjadi alasan ketidak adanya pelatihan kerajinan tangan bagi anak SD. Padahal kondisi lingkungan di sekitar juga cukup berpotensi untuk dijadikan bahan pelatihan seni kerajinan tangan, misalnya barang bekas dan benda alam.

\section{KAJIAN PERSOALAN}

Berdasarkan survei yang dilakukan oleh mahasiswa KKN di arprodi PGSD Universitas Muhammadiyah Gresik di SDN Sukalela untuk pengajaran seni kami menarik beberapa permasalahan, diantaranya:

1. Kurang optimalnya pelaksanaan pengajaran seni keterampilan termasuk seni kerajinan tangan

2. Kurangnya kepedulian siswa terhadap keadaan lingkungan sekitar

3. Kurangnya motivasi siswa terhadap suatu pemanfaatan barang bekas
4. Kurangnya minat guru untuk memberikan sebuah pengajaran seni keterampilan khususnya pelatihan seni kerajinan tangan dari barang bekas

Dari pemasalahan yang terjadi, pelatihan akan seni keterampilan khususnya seni kerajinan tangan menjadi tidak terlaksana. Padahal sebenarnya dengan adanya pengajaran berkarya seni terhadap anak tingkat sekolah dasar khususnya sekolah daerah pedesaan sangatlah dibutuhkan siswa untuk meningkatkan keterampilan dan kreativitasnya agar tidak tertinggal oleh sekolah-sekolah diperkotaan, serta mampu menciptakan rasa sosial untuk menjaga lingkungan sekitar.

Iryanti dan Jazuli (vol.2, 2001) mengungkapkan bahwa tujuan seni hendaknya diarahkan pada pemahaman sepenuhnya terhadap seni berdasarkan nilai-nilai sosial budaya. Sehingga memberikan peluang bagi siswa untuk melakukan kegiatan kreatif. Kegiatan kreatif itu sendiri merupakan manifestasi dari kemampuan anak untuk berkomunikasi dengan lingkungan sekitar. Dengan hal itu keterampilan anak semakin terpupuk dan kreativitas anak berkembang.

Dari itu, kita tahu bahwa pengajaran seni termasuk pelatihan seni keterampilan itu cukup penting untuk perkembangan keterampilan siswa di masa yang akan datang, dengan hal itu mereka bisa terlatih untuk menjadi terampil, aktif, kreatif dan inovatif. Dengan adanya pelatihan seni kerajinan tangan khususnya dari barang bekas, mampu memberi edukasi kepada anak SD tentang pemanfaatan barang bekas, memberi kesadaran kepada siswa untuk peduli terhadap lingkungan, serta memberi motivasi kepada guru bahwa pelatihan seni kerajinan tangan itu juga penting dan bisa digunakan untuk referensi media pembelajaran di sekolah. 


\section{JTIEE Vol.1 No. 215 Desember 2017}

Pelatihan seni kerajinan tangan dari barang bekas tersebut bisa dilakukan dengan memanfaatkan barang bekas yang ada di lingkungan sekitar. Dengan adanya contoh dan pengarahan dari pengajar, siswa menjadi tahu tentang bagaimana cara pengolahan barang bekas tersebut bisa menjadi sesuatu yang mempunyai fungsi baru dan memunculkan ide baru pada diri seorang anak untuk berinovasi membuat suatu karya yang lebih menarik. Keterampilan dan kreativitas yang dimiliki seorang anak tentu berbeda, sehingga mereka bisa menuangkan kemampuannya tersebut ke dalam sebuah karya yang berbeda, misalnya mereka berkreasi memilih warna maupun membuat hiasan pada karya.

\section{METODE PELAKSANAAN}

Pelaksanaan kegiatan ini dilakukan dengan melakukan observasi ke SDN Sukalela terlebih dahulu, dengan tujuan untuk mengetahui bagaimana proses pengajaran seni keterampilan tentang kerajinan tangan dan sejauh mana pengajarannya terhadap siswa di sekolah tersebut, serta untuk mengetahui waktu yang tepat untuk memberikan pelatihan seni kerajinan tangan pada anak-anak di SDN Sukalela.

Pelaksanaan dari kegiatan pengajaran seni kerajinan tangan dari barang bekas dilaksanakan sebanyak empat kali pertemuan selama KKN berlangsung, sedangkan untuk waktunya dilakukan diluar jam sekolah. Siswa kelas 3 dan 4 dilakukan mulai pukul 16.0017.20 WIB, sedangkan siswa kelas 5 dan 6 dilaksanakan mulai pukul 14.00-16.00 WIB. Pelatihan untuk kelas 3 dan kelas 4 dilaksanakan selama 2 kali pertemuan, selanjutnya 2 kali pertemuan berikutnya untuk kelas 5 dan kelas 6. Berikut jadwal kegiatan pelatihan seni kerajinan tangan dari barang bekas.

Tabel 1. Jadwal Kegaiatan

\begin{tabular}{|l|l|l|l|}
\hline No & Kegiatan & Siswa & Waktu \\
\hline 1 & $\begin{array}{l}\text { Membuat } \\
\text { bunga dari } \\
\text { botol } \\
\text { bekas }\end{array}$ & $\begin{array}{l}\text { Kelas } \\
3 \& 4\end{array}$ & $\begin{array}{l}\text { Hari } \\
\text { ke-19 }\end{array}$ \\
\hline 2 & $\begin{array}{l}\text { Membuat } \\
\text { tempat } \\
\text { pensil dari } \\
\text { botol } \\
\text { bekas dan } \\
\text { kain } \\
\text { flannel }\end{array}$ & $\begin{array}{l}\text { Kelas } \\
\text { Memb }\end{array}$ & $\begin{array}{l}\text { Hari } \\
\text { ke-20 }\end{array}$ \\
\hline 3 & $\begin{array}{l}\text { Membuat } \\
\text { bunga dari } \\
\text { tempat } \\
\text { telur bekas }\end{array}$ & Kelas & Hari \\
ke-21, \\
22
\end{tabular}

Kegiatan pelatihan tersebut dilakukan di SDN Sukalela dengan jadwal di luar jam sekolah. Sedangkan untuk alat dan bahan yang digunakan untuk kegiatan pelatihan seni kerajinan tangan tersebut diantaranya botol bekas, tempat telur bekas, cat,cait air, tinner, kuas, gunting, cutter, kain flannel, lem tembak, spidol/pen, kertas origami, dan mata boneka.

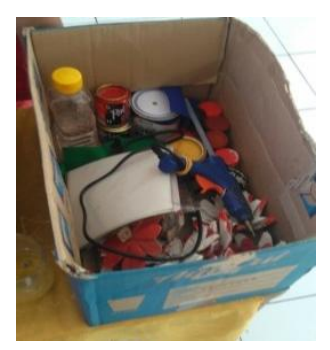

Gambar 1. Alat dan bahan pembuatan bunga dan tempat pensil dari botol bekas 


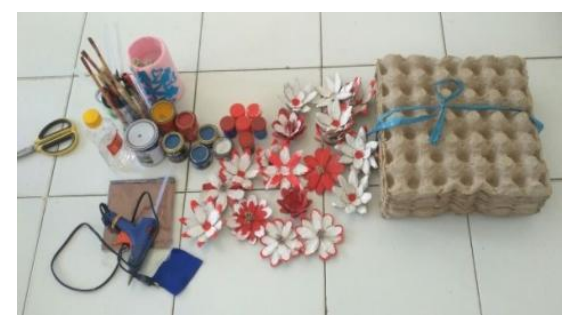

Gambar 2. Alat dan bahan pembuatan bunga dari tempat telur bekas

Untuk kegiatan pelatihan itu sendiri, dilakukan dengan cara sebagai berikut :

1. Pembuatan Bunga dan Tempat Pensil Dari Botol Bekas

Pembuatan bunga dan tempat pensil dari botol bekas dilakukan oleh siswa kelas 3 dan kelas 4 SD. Mereka membawa botol bekas dan gunting dari rumah. Pengajar menyediakan alat dan bahan-bahan lainnya kemudian memberi contoh serta arahan kepada siswa tentang cara pembuatan karya yang dimaksud. Mereka bisa berkreasi membuat bunga dan tempat pensil yang sesuai kemampuan mereka.

2. Pembuatan Bunga Dari Tempat Telur Bekas

Pembuatan bunga dan tempat pensil dari botol bekas dilakukan oleh siswa kelas 5 dan kelas 6 SD. Mereka membawa gunting dari rumah. Pengajar menyediakan alat dan bahan-bahan lainnya kemudian memberi contoh serta arahan kepada siswa tentang cara pembuatan karya yang dimaksud. Mereka berkreasi membuat bunga dan memberi warna sesuai keinginannya.
JTIEE Vol.1 No. 215 Desember 2017

\section{HASIL DAN PEMBAHASAN}

Sesuai dengan permasalahan yang terjadi bahwa pelatihan seni kerajinan tangan masih belum terlaksana di sekolah dasar tertentu. Dengan adanya pelatihan seni kerajinan tangan dari barang bekas yang dilakukan oleh siswa KKN dari prodi PGSD, siswa di SDN Sukalela jadi lebih tau cara pemanfaatan barang bekas untuk dijadikan kerajinan tangan serta keterampilan dan kreativitas siswa menjadi terpupuk dan berkembang, pengetahuannya pun berkembang sehingga daya inovasinya muncul.

Siswa kelas 3 dan 4 SDN Sukalela cukup aktif dan mudah untuk menerima pengetahuan baru, namun selama proses belajar di sekolah, pengajaran akan seni ketarmpilan masih kurang, padahal guru bisa memanfaatkan barang bekas di sekitarnya untuk dijadikan pembelajaran. Dengan adanya hal itu, kami memberi pelatihan kepada siswa kelas 3 dan 4 SDN Sukalela untuk membuat kerajinan dari barang bekas yaitu botol bekas, melihat begitu banyaknya botol bekas yang tidak terpakai di sekitar lingkungan mereka, kami mengajarkan kepada mereka cara membuat bunga dan tempt pensil dari botol bekas sehingga mereka tahu bahwa botol beas bisa dijadikan kerajinan tangan yang bernilai estetis dan bisa difungsikan lagi menjadi sesuatu yang bermanfaat. Perlahan-lahan pengetahuan mereka terhadap seni keteraampilan barang bekas menjadi bertambah dan keterampilan maupun kreativitasnya semakin maju. 


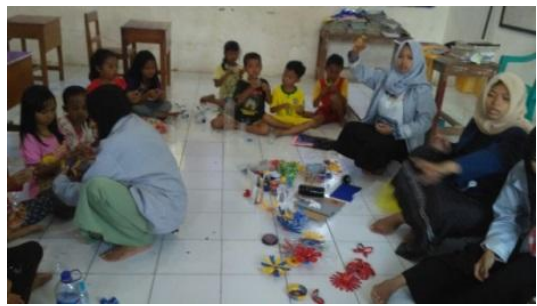

Gambar 3. Pelatihan Membuat Bunga dari Botol Bekas

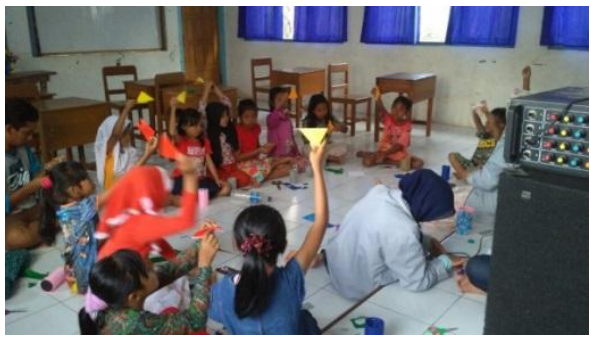

Gambar 4. Pelatihan Membuat Tempat Pensil

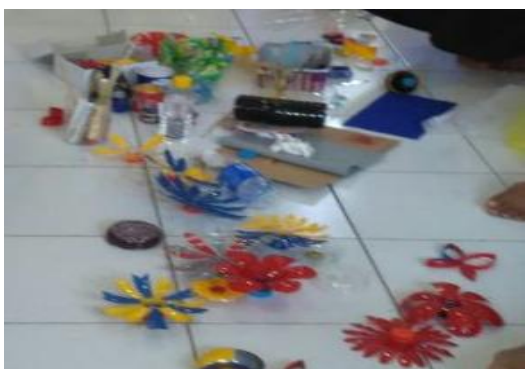

Gambar 5. Hasil Jadi Bunga dari Botol Bekas

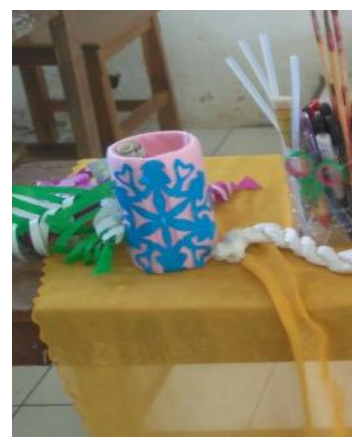

Gambar 6. Hasil Jadi Tempat Pensil

Siswa kelas 5 dan 6 SDN Sukalela juga cukup aktif dan terampi, pengetahuan dan pengajaran seni keterampilan dirasa masih
JTIEE Vol.1 No. 215 Desember 2017

kurang. Oleh karena itu kami memberi pelatihan seni kerjinan tangan dari baarang bekas kepada mereka namun barang bekas yang digunakan adalah tempat telur yang tidak terpakai. Dengan adanya barang bekas tersebut, kami mengajarkan kepada mereka cara membuat bunga yang cantik dari tempat telur. Setelah mereka membuat kerajinan tangan, mereka menjadi tahu bahwa tempat teluryang tidak terpakai bisa diamanfaatkan untuk dijadikan sesuatu yang bernilai estetis. Tentu hal itu menambah pengetahuan serta keterampilan maupun kreativitas mereka. Dan hasil karya tersebut bisa dijadikan hiasan ruangan.

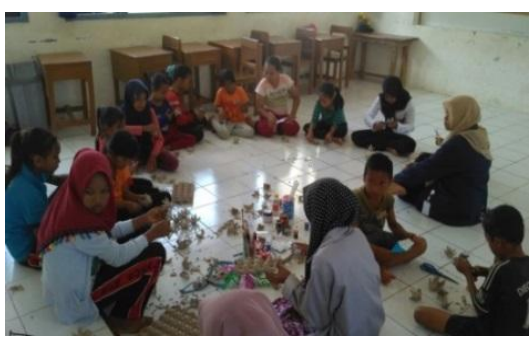

Gambar 7. Pelatihan Pembuatan Bunga dari Tempat Telur

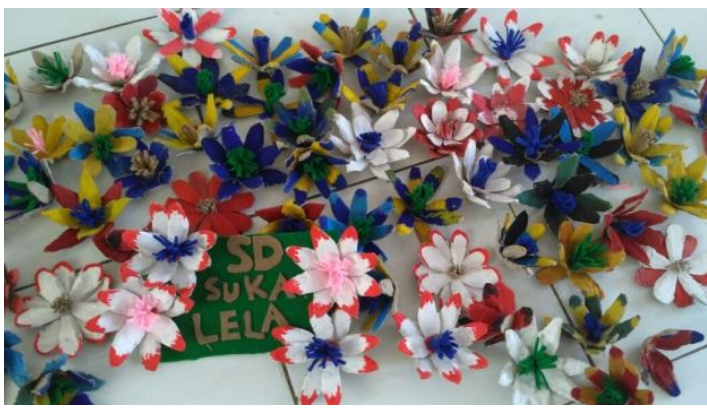

Gambar 8. Hasil Jadi Bunga Dari Tempat Telur Bekas

Pelatihan yang diberikan kepada kepada ke empat kelas di SDN Sukalela tersebut dilaksanakan di luar jam sekolah, tujuannya agar waktu proses pengajaran menjadis menjadi 


\section{JTIEE Vol.1 No. 215 Desember 2017}

longgar dan tidak memburu waktu belajar mereka disekolah sehingga materi yang mereka dapatkan bisa terserap dengan baik. Selain itu waktu pelatihan tersebut kami berikan secara berbeda-beda tujuannya agar tidak bercampur dengan materi pelatihannya dan menghindari konflik anatar siswa kelas tinggi dengan siswa kelas rendah.

\section{SIMPULAN DAN SARAN}

\section{a. Simpulan}

Pelatihan membuat seni kerajinan tangan yang di lakukan di SDN Sukalela dilakukan selama 4 kali pertemuan. Pengajar dalam pelatihan ini yaitu mahasiswa dari prodi PGSD dengan bantuan dari prodi lain untuk ikut membantu mendampingi anak-anak yang hadir mengikuti pelatihan.

Berdasarkan sebuah pengamatan di SDN Sukalela, pelatihan seni ketarmpilan masih belum terlaksana dengan baik, khususnya seni kerajinan tangan belum ada. Pendidik kurang mampu memberikan suatu pelatihan seni keterampilan kepada siswa secara optimal, melihat kondisi pendidik yang kurang mendukung serta kurangnya waktu guru untuk memberikan pengajaran jika diajarkan pada waktu jam sekolah.

Hasil dari pelatihan yang telah dilakukan mahasiswa KKN untuk siswasiswi di SDN Sukalela adalah :

1) Mampu membuat bunga dari botol bekas

2) Mampu membuat tempat pensil dari botol bekas dan kain flanel

3) Mampu membuat bunga dari tempat telur bekas
4) Menjadi aktif, kreatif, terampil dan peduli terhadap lingkungan.

\section{b. Saran}

Setelah melaksanakan kegiatan pelatihan seni kerajinan tangan dari barang bekas, maka saran yang dapat kami berikan untuk SDN Sukalela adalah :

1. Pelatihan-pelatihan seni keterampilan khususnya kerajinan tangan sangat penting untuk perkembangan keterampilan dan kreativitas yanga ada pada siswa sekolah dasar sehingga harus dilaksanakan secara dengan baik.

2. Setelah dilakukannya pelatihan kepada siswa-siswi di SDN Sukalela, diharapkan para guru memberi kesempatan kepada siswa untuk membuat kerajinan tangan dari barang bekas yang mana hasilnya nanti bisa digunakan untuk menghias kelas

3. Barang bekas yang ada disekitar sekolah maupun di sekitar rumah hendaknya dimanfaatkan dengan baik, sehingga minat dan motivasi dari para pengajar sangat diperlukan bagi siswa.

\section{REFERENSI}

Iryanti, V. Eny \& Jazuli, M. (2001). Mempertimbangkan Konsep Pendidikan Seni. Harmonia Jurnal Pengetahuan Dan Pemikiran Seni. (vol 2, No.2 Tahun 2001).

https://media.neliti.com/media/publication/6278 8-ID-none.pdf

Masunah, Juju. (2010). Pelatihan Pengembangan Bahan Ajaran Seni Budaya Berbasis Potensi Local Bagi Guru Sekolah Dasar. Junal Penelitian Dan Pendidikan. http://jurnal.upi.edu/file/Juju_M.pdf 


\section{JTIEE Vol.1 No. 215 Desember 2017}

Raharjo, Timbul. 2011. Seni Kriya dan Kerajinan. Yogyakarta: Program Pascasarjana Institut Seni Indonesia Yogyakarta.

http://digilib.isi.ac.id/1073/

Sefmiwati, S.Sn. (2016). Pengembangan Pembelajaran Seni Kriya Menggunakan Teknik Pemodelan Berbasis Pendekatan Saintifik. Jurnal Penelitian Guru Indonesia. (vol 1, No. 1 Tahun 2016). http://jurnal.iicet.org/index.php/jpgi/article/vie $\mathrm{w} / 46$

Widyaningrum, Ari \& Rofian. 2015. Barang Bekas Sebagai Media Penciptaan Karya Seni Dalam Pembelajaran Seni Rupa Kelas V SD 1 Gribig Kudus. Jurnal UPGRIS.

http://journal.ac.id/index.php/malihpeddas/artic le/view/849 